\title{
Daily Stress, Illness, and Use of Health Services in Young Families
}

\author{
KLAUS J. ROGHMANN ${ }^{[261}$ AND ROBERT J. HAGGERTY \\ The University of Rochester, Department of Pediatrics, Rochester, New York, USA
}

\begin{abstract}
Extract
Family life crises have been suggested as etiologic factors in common illness and in precipitating the use of health services. In this study both relations were studied by means of a daily diary kept by 512 families.

Comparison of the observed onset of illness in mothers on the first day of a stress episode with the expected onset revealed that illness was 2.5 times more likely than expected by chance. If no illness was present, stress increased utilization of medical services. If there was illness, it decreased utilization for mothers and increased it for young children. The site of care was an important variable. The probability of telephone calls, visits to the outpatient department (OPD) and emergency department (ED) was doubled in "stress-combined illnesses," although there was little change in the probability of office visits or visits to other clinics at these times. Length of illness was also relevant. One-day-illness episodes have lower chances of medical contact with stress than without, for both mother $(1.5 \%$ with stress and $2.1 \%$ without) and child $(4.0 \%$ with stress and $6.4 \%$ without). For longer illness episodes $(2-5$ days) the probability of utilization increases for the child when stress is present (from $0.9 \%$ to $15.5 \%$ ), but decreases for the mother (from $10.4 \%$ to $8.4 \%$ ).
\end{abstract}

\section{Speculation}

The greatest future challenge lies in controlled trials of methods to reduce internal stress and the resultant perceived illness. This would reduce acute illnesses and place fewer and more rational demands on the health care system. Finally, we have to face the question of whether we should work towards reducing the external stresses of life or limit ourselves to "immunizing" people against inevitable life crises by strengthening their ability to handle stress without becoming physically or mentally ill and without making undue demands on the health care system.

\section{Introduction}

Family life stress and illness have been positively correlated in many previous studies $[4,5,7,8,15,18,20]$, although the physiologic mechanisms for this altered host resistance are not yet entirely clear [14]. Sociologists $[3,12]$ and psychologists $[11,13]$ have studied the sources and consequences of stress, and the coping process itself. Although the relation between long term stress and the onset of disease is well documented [7-9], we do not yet have information on the relations between daily or acute upsetting events, the frequency of perceived acute illness, and a visit to the doctor. Even the frequency of such common family crises in a normal population has not yet been reported. In this 
study we have documented, for a random sample of families with children under 18 , the incidence and course of upsetting events, and assessed their relation to everyday illness and to the use of health services.

\section{Concepts}

The terms crisis, stress, and upsetting event are used interchangeably in this study, although we recognize that they are used frequently to describe two separate parts of the same process. The term crisis or stressor usually refers to the external event, the term stress or tension to the individual's response, either emotional or physiologic or both. In this paper we are dealing only with external upsetting events. Stress was defined as any event perceived by the family as upsetting, excluding illness, that occurred in the family on a given day and required some type of coping behavior. Loss of job, marital discord, divorce, police contacts, death in the family, arguments over children's behavior, financial problems, or upsets with employer or neighbors are examples of such events.

The term illness refers to perceived illness only. Illness was defined as the presence of any perceived symptom in a family member, as reported by the mother. We recognize that objective examinations would yield different frequencies than those we found. Our concern was with perceptions that could precipitate medical contacts. Most of these perceived illnesses were minor, e.g., fever, coughs, headaches, or colds. There were a number of serious illnesses (one mother died during our observation period), but they were too infrequent for statistical analysis.

The term utilization refers to any contact with the medical care system, including telephone calls. Our focus in this paper is on short term processes as they influence the decision to see a doctor. As a result we had to rely more on social science techniques than is usually the case in epidemiologic research where disease frequencies are to be explained and not patient behavior.

\section{Methods}

$A$ random sample of 512 families with children under 18 years of age was selected in 1969 by methods described previously [19] from Monroe County, an upstate New York area, then of about 700,000 people, with the city of Rochester as its center.

An initial household interview was conducted to determine demographic data, recent illnesses, use of health services, and chronic or long term stress [21]. In addition, the mother was asked to keep a diary on which she recorded daily, for 28 consecutive days, the presence in the family of upsetting events (at work, in the house, about the children, with the husband etc.), illness, and any use of health services. The mothers were paid a small amount for this, and were periodically checked, by telephone or house call, for proper recording. If no special event occurred on a given day, the mothers checked an appropriate box in the diary. If there was no entry for a given day in the calendar, the variables for this day were coded as having a "missing value." Compliance with the diary keeping instructions was generally very high. In only a few instances was compliance low, in which case that diary was excluded from the study [22]. The overall completion rate was $82 \%$.

Coders evaluated the amount of coping required by any special event reported. No table of life crisis units as in the "Social Readjustment Rating Scale" [9] was feasible for our upsetting event coverage, but an example list with stress weights guided the coder [3]. The sum of the stress weights from the four areas of family life (work, children, marriage, anything else) checked daily was used as an overall stress score. The large volume of diary data $(2,547$ persons in the 512 families were described on 28 days each) required special analytic techniques in addition to an initial standard survey analysis. Markov chain analysis was applied to study changes from day to day. Episodes of stress in families and episodes of illness and of care in family members were identified. Such episodes could then be used as units of analysis and described as to length, type, and context.

\section{Results}

The diary data gave us detailed information of 28 consecutive days of 1,081 adults and 1,466 children: all together, on 71,316 person-days. On any given day there was a $30 \%$ chance for each family to be in episode of stress. Most of these upsetting events were rated mild (score 1-3) by our coders. Only 10\% were severe (score 4-12).

A health complaint (indicator for illness) was reported in the mother on $25.3 \%$ of all days and on $17.4 \%$ for the youngest child. Medical contacts (including telephone calls) on any given day were, as would be expected, much less frequent than stress or illness. The 2,547 persons reported 1,039 uses of health services during the 28 days. The chance of a medical con- 
tact on any given day was $1.97 \%$ for mothers and $1.87 \%$ for the youngest child. It is clear that stress and illness, as measured here, are frequent events in the life of the average family, and that only a small fraction of complaints require and receive a physician's attention.

If we had used a conventional survey approach, i.e., if we had not interviewed 512 mothers about 28 days each, but 14,336 mothers about 1 day each, we would not have found strong relations. In that case, easily simulated with out data, stress would correlate only moderately with illness (For mothers $r=+0.19$, for children $r=+0.10$ ). There would have been practically no relation between stress and utilization $(\mathrm{r}=$ +0.02 for mothers, $r=+0.03$ for children).

However, it can rightly be pointed out that the product-moment correlation coefficients for the relations are low because of lack of variance and uneven marginal distributions. Other measures for the strength of these relations are more appropriate. Table I is limited, therefore, to a comparison of the probabilities for a medical contact as a function of stress and illness. The probability for a doctor contact, not surprisingly, increases fivefold for mothers (from 1\% to $5 \%$ ) and 10-fold for youngest children (from $0.7 \%$ to $7 \%$ ) due to this presence of illness. The probability for illness doubles for mothers (from $19 \%$ to $37 \%$ ) and increases $50 \%$ for children (from $15 \%$ to $23 \%$ ) on days of stress.

Whether stress reduces or increases utilization can best be seen by comparing the conditional probabilities for utilization depending on whether illness is present or not. Stress generally increased the probability of utilization if there was no illness $(+30 \%$ for mothers, $+9 \%$ for children). If there was illness, it decreased the probability of utilization for mothers $(-15 \%)$ and increased the probability of utilization for children $(+23 \%)$. Stress thus only leads to increased utilization for children; for mothers there is an underutilization.

Where do the "stress-induced" medical contacts occur? Table II shows the important point that stress increases use of health services only in those places that are easily accessible. The probability of telephone calls, visits to the outpatient and emergency department are all doubled in "stress-combined illnesses" while there is little change in the probability of office visits or visits to other clinics (subspecialties). Thus it is only a selected type of medical contacts (phone calls

Table II. Probability of utilization by place of contact as a function of stress and illness, using person-days (Monroe County, New York, 1969)

\begin{tabular}{|c|c|c|c|c|c|}
\hline \multirow[b]{2}{*}{ Place of contact } & \multicolumn{5}{|c|}{ Probability of utilization } \\
\hline & $\begin{array}{l}\text { I: no } \\
\text { S: no }\end{array}$ & $\begin{array}{l}\text { I: no } \\
\text { S:yes }\end{array}$ & $\begin{array}{l}\text { I: yes } \\
\text { S: no }\end{array}$ & $\begin{array}{l}\text { I: yes } \\
\text { S: yes }\end{array}$ & Any day \\
\hline Phone & 0.01 & 0.01 & 1.04 & 2.22 & 0.25 \\
\hline Office & 0.37 & 0.55 & 2.45 & 2.57 & 0.75 \\
\hline $\begin{array}{l}\text { Out patient depart- } \\
\text { ment }\end{array}$ & 0.05 & 0.17 & 0.89 & 1.62 & 0.27 \\
\hline Emergency. & 0.01 & 0.00 & 0.36 & 0.89 & 0.10 \\
\hline Other clinics & 0.05 & 0.12 & 0.18 & 0.21 & 0.09 \\
\hline Total probability, \% & 0.47 & 0.85 & 4.93 & 7.51 & 1.46 \\
\hline $\begin{array}{l}\text { Total medical con- } \\
\text { tacts }\end{array}$ & 199 & 152 & 326 & 362 & 1,039 \\
\hline $\begin{array}{l}\text { Total days in each } \\
\text { group }\end{array}$ & 41,959 & 17,923 & 6,615 & 4,819 & 71,316 \\
\hline
\end{tabular}

Table I. Distribution of person-days over the eight combinations of states of the three variables, and the probabilities for a medical contact as a function of stress (S) and illness (I)

\begin{tabular}{|c|c|c|c|c|c|c|c|}
\hline Medical contact & $\begin{array}{l}\text { I: no } \\
\text { S: no }\end{array}$ & $\begin{array}{l}\text { I: no } \\
\text { S: yes }\end{array}$ & I: no & $\begin{array}{l}\text { I: yes } \\
\text { S: no }\end{array}$ & $\begin{array}{l}\text { I: yes } \\
\text { S: yes }\end{array}$ & I: yes & Total \\
\hline \multicolumn{8}{|l|}{ Total utilization } \\
\hline No & 41,760 & 17,771 & 59,531 & 6,289 & 4,457 & 10,746 & 70,277 \\
\hline Yes & 199 & 152 & 351 & 326 & 362 & 688 & 1,039 \\
\hline$P_{t} y>, \%$ & 0.47 & 0.85 & 0.59 & 4.93 & 7.51 & 6.02 & 1.46 \\
\hline \multicolumn{8}{|l|}{ Maternal utilization } \\
\hline No & 7,943 & 2,734 & 10,677 & 1,826 & 1,552 & 3,378 & 14,055 \\
\hline Yes & 71 & 32 & 103 & 104 & 74 & 178 & 281 \\
\hline$P(U), \%$ & 0.89 & 1.16 & 0.96 & 5.39 & 4.55 & 5.01 & 1.96 \\
\hline \multicolumn{8}{|l|}{ Youngest child's utilization } \\
\hline No & 8,411 & 3,374 & 11,785 & 1,376 & 911 & 2,287 & 14,072 \\
\hline Yes & 59 & 26 & 85 & 98 & 81 & 179 & 264 \\
\hline$P(U), \%$ & 0.70 & 0.76 & 0.72 & 6.65 & 8.17 & 7.26 & 1.84 \\
\hline \multicolumn{8}{|l|}{ Other members' utilization } \\
\hline No & 25,406 & 11,663 & 37,069 & 3,087 & 1,994 & 5,081 & 42,150 \\
\hline Yes & 69 & 94 & 163 & 124 & 207 & 331 & 494 \\
\hline$P(U), \%$ & 0.27 & 0.80 & 0.44 & 3.86 & 9.40 & 6.12 & 1.16 \\
\hline
\end{tabular}


and emergency room) and visits in the public sector (OPD and ED) that are stress sensitive. The appointment system in the private office creates a barrier to care that keeps stress-induced demand out of the office. This finding has important implications for managing demand for services in different settings.

The "survey approach" analysis presented up to now, using, in a simulation style, person-days as if 1 day in the calendar was independent of the other, gave only part of the picture and ignored valuable additional information available through our study design. The survey approach was a static analysis that could correlate only events on a given day. Conditional probabilities should, therefore, not only be computed for one event given the presence of another event on the same day, but also as a function of the presence of the same event on the previous day, and the day before the previous day. Table III presents such results for mother-days. The best predictor is the previous day's state. If an event (stress, illness, medical contact) occurred the previous day, its occurrence today is 3-6 times. as likely than if the event did not occur the previous day. The probability of stress is $59 \%$ if stress was reported on the previous day, but only $17 \%$ if no stress was reported. Similar changes can be observed for illness $(55 \%$ compared with $14 \%)$ and for medical contacts $(11.9 \%$ compared with $1.7 \%)$. Consideration of

Table III. Probability of events as a function of occurrence of same event on previous days (PD), using person-days (Monroe County, New York, 1969)

\begin{tabular}{|c|c|c|c|c|}
\hline & $\begin{array}{l}\text { On any } \\
\text { day, \% }\end{array}$ & $\begin{array}{l}\text { If same } \\
\text { event } \\
\text { occurred } \\
\text { on PD, \% }\end{array}$ & $\begin{array}{c}\text { If same } \\
\text { day } \\
\text { before } \\
\text { PD }\end{array}$ & $\begin{array}{l}\text { event occurred } \\
\text { on } \\
\text { On PD, \% }\end{array}$ \\
\hline \multirow[t]{2}{*}{ Family stress } & 30.0 & No: 17.4 & $\begin{array}{l}\text { No } \\
\text { Yes }\end{array}$ & $\begin{array}{l}\text { No: } 14.6 \\
\text { No: } 29.1\end{array}$ \\
\hline & & Yes: 59.2 & $\begin{array}{l}\text { No } \\
\text { Yes }\end{array}$ & $\begin{array}{l}\text { Yes: } 37.5 \\
\text { Yes: } 73.7\end{array}$ \\
\hline \multirow[t]{2}{*}{ Mother illness } & 24.4 & No: 14.1 & $\begin{array}{l}\text { No } \\
\text { Yes }\end{array}$ & $\begin{array}{l}\text { No: } 12.5 \\
\text { No: } 23.7\end{array}$ \\
\hline & & Yes: 55.7 & $\begin{array}{l}\text { No } \\
\text { Yes }\end{array}$ & $\begin{array}{l}\text { Yes: } 39.3 \\
\text { Yes: } 68.3\end{array}$ \\
\hline \multirow[t]{2}{*}{$\begin{array}{l}\text { Mother medical } \\
\text { contact }\end{array}$} & 1.9 & No: 1.7 & $\begin{array}{l}\text { No } \\
\text { Yes }\end{array}$ & $\begin{array}{ll}\text { No: } & 1.6 \\
\text { No: } & 8.6\end{array}$ \\
\hline & & Yes: 11.9 & $\begin{array}{l}\text { No } \\
\text { Yes }\end{array}$ & $\begin{array}{l}\text { Yes: } 6.2 \\
\text { Yes: } 51.5\end{array}$ \\
\hline
\end{tabular}

Table $I V$. Sequence of stressful events over the 28 days of the health calendar $(n=512 \text { families })^{1}$

$$
\begin{aligned}
& \text { Transition probabilities } \\
& P,+1 \text { Day } t+1 \mathrm{Q},+1
\end{aligned}
$$

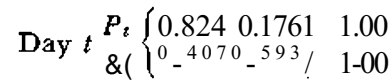

$$
\begin{aligned}
& \text { Characteristics of process } \\
& P=0.698 \\
& \bar{Q}=0.302 \\
& L_{P}=5.68 \\
& L_{Q}=2.45 \\
& L_{P+Q}=8.13 \\
& E=28 / 8.13=3.44 \\
& D_{Q}=3.44 \times 2.45=8.56
\end{aligned}
$$

${ }^{1} \vec{P}$ : Probability of no stress on any day; $\bar{Q}$ : probability of stress on any day; $L p$ : average length of stress-free episode; $L Q$ : average length of stress episode; $L_{P+Q}$ : average length of cycle; $E$ : average number of episodes per any 28 -day sequence; $D Q$ : average number of stress days per any 28 -day sequence.

the state of a variable on the day before the previous day leads to a further specification of probabilities, but the gain is much less dramatic. This finding suggests that the clustering of events over time may fit the model of a regular Markov chain [24] process [10]. Under the assumption of this model, relatively simple formulas can be used to describe such a process. We only need a matrix of the transition probabilities $R_{i j t}$ representing the probabilities of a change from state $i$ to state $j$ over the period $t$ to $t+1$. Table IV gives the matrix of transition probabilities for stress processes in our sample of 512 families. Certain deductions are possible from this matrix. The probability vector, $P_{i t}$, representing the probabilities that an individual in any of the $i$ states at time $t$, can be computed. Average length of stress episodes (about 2.45 days) can be determined. These episodes are separated from each other by stress-free periods that average 5.68 days. In a similar way we can make deductions about illness episodes and medical care episodes. We can fit more sophisticated models to the data to see which one represents them best.

The static survey analysis used the person-day as the unit of analysis. The dynamic analysis added the time dimension and assumed a continuous stream of days during which people move through various states of stress, illness, and medical contacts. It may be even more natural to use an intermediate unit such as an "episode" [18]. In a first analysis of episodes, we defined a stress episode as a set of consecutive days with at least 1 problem to cope with each day, though not 
necessarily the same problem. One-day episodes were permitted. Our 512 sample families experienced 1,877 stress episodes. About $10 \%$ of the families had no episode, $39 \%$ had between 1 and 3 episodes, $37 \%$ between 4 and 6 episodes and the remaining 14\% had 7 or more episodes. The average number of episodes over the 28-day period was 3.7 per family; the average length of an episode was 2.3 days. The fact that this empiric test closely approximated the values predicted from the Markov model can be seen as evidence for the presence of a Markov process. The "episode approach" can provide us with some information that the Markov model cannot. Indexing forward and backward in the calendar permits us to register illness frequency of family members on days before, during, and after a stress episode. From our earlier analyses we knew the average and conditional probabilities for illness. To the extent that illness frequencies observed during or after stress episodes deviate from the expected frequencies (under the assumption of independence), we can draw conclusions about causal relations.

When we compare the observed onset of illness in mothers on the first day of a stress episode (Table V) with the expected onset figures, we find a value 2.5 times higher ( $25 \%$ observed against $10 \%$ expected). This is evidence that the general phenomenon of increased illness with stress is not only a reality for major diseases or for long term stress, but also for minor illness and short term stress. This may turn out to be the most important aspect of the study.

But for the purpose of this paper we were more concerned with episodes of illness and their relation to the utilization of medical care as a function of stress. An episode of illness was defined as any sequence of health complaint days, including 1-day episodes. The 2,547 persons in the sample had 5,256 episodes of illness. As we might expect, children were more likely than mothers to have a medical contact when sick (6.5\% of mother illness episodes and $11.8 \%$ of child

Table $V$. Frequency of changes in maternal illness observed during 1,153 1-day stress episodes

\begin{tabular}{|c|c|c|c|c|}
\hline & \multicolumn{4}{|c|}{ Stress episodes } \\
\hline & \multicolumn{2}{|c|}{ Materniil illness } & \multirow{2}{*}{ Expected, \% } & \multirow{2}{*}{ Observed, $\%$} \\
\hline & Before & During & & \\
\hline \multirow[t]{2}{*}{ No change } & No & -* Nol & \multirow{2}{*}{78.2} & \multirow{2}{*}{68.1} \\
\hline & Yes & -9) Yes/ & & \\
\hline Onset & No & $\rightarrow$ Yes & 10.9 & 25.2 \\
\hline End & Yes & $-->\mathrm{No}$ & 10.9 & 6.8 \\
\hline
\end{tabular}

Table VI. Frequency of medical contact during illness episodes as a function of length of episode and stress

\begin{tabular}{|c|c|c|c|c|c|c|}
\hline & \multicolumn{2}{|c|}{ All episodes } & \multicolumn{2}{|c|}{ No sstress } & \multicolumn{2}{|c|}{ With stress } \\
\hline & $P, \%$ & $N$ & $p, \%$ & $n$ & $P, \%$ & $n$ \\
\hline \multicolumn{7}{|l|}{$\begin{array}{c}\text { Mother illness } \\
\text { episodes }\end{array}$} \\
\hline 1 day long & 1.8 & 995 & 2.1 & 513 & 1.5 & 482 \\
\hline 2-5 days long & 9.2 & 545 & 10.4 & 222 & 8.4 & 323 \\
\hline $\begin{array}{l}5 \text { or more } \\
\text { days }\end{array}$ & 36.9 & 103 & 36.2 & 47 & 37.5 & 56 \\
\hline $\begin{array}{l}\text { All } \\
\text { Youngest child } \\
\text { illness epi- } \\
\text { sodes }\end{array}$ & 6.4 & 1,643 & 6.5 & 782 & 6.4 & 861 \\
\hline 1 day long & 5.3 & 582 & 6.4 & 329 & 4.0 & 253 \\
\hline 2-5 days long & 12.5 & 343 & 9.0 & 156 & 15.5 & 187 \\
\hline $\begin{array}{l}5 \text { or more } \\
\text { days }\end{array}$ & 47.0 & 100 & 51.2 & 41 & 44.1 & 59 \\
\hline All & 11.8 & 1,025 & 10.6 & 526 & 13.0 & 499 \\
\hline
\end{tabular}

illness episodes received medical attention). The longer the illness episode, the more likely was medical contact $36.9 \%$ and $47.0 \%$ for mothers and children, respectively, during 5-day-plus illness episodes compared with $1.8 \%$ and $5.3 \%$ for 1-day-illness episodes). There is a complex relation between length of illness, the person who seeks care (mother or child), stress, and medical contact (Table VI). One-day-illness episodes have lower chances of medical contact with stress than without, for both mother (1.5\% with stress and $2.1 \%$ without) and child (4.0\% compared with 6.4\%). For slightly longer illness episodes (2-5 days) the probability of utilization increases for the child when stress is present (from $9.0 \%$ to $15.5 \%$ with stress), but not for the mother (decrease from 10.4\% with no stress to $8.4 \%$ with stress). For longer illness episodes (5 days or longer) stress does not seem to influence the probability of a medical contact, but our figures are too small to make a definite statement on this. In general then, people seem to assume the sick role \{i.e., seek care in the presence of a symptom) less readily when the symptoms can be "explained away" as "only" the result of short term stress. Mothers, especially, may recognize stress as a cause of their own illness and do not regard it as legitimate to take the sick role for such illness. They do, however, regard it as legitimate to assign the sick role to their children for stress-related illness and actually do so more frequently for such illness than for stress-unrelated illness. 


\section{Discussion}

There is clear evidence from this study of the potent effect that environmental stress has on increasing one's chance of becoming ill, even if only minor daily events are examined. Although this was not the major thrust of our study, it is clear that this aspect merits a greater amount of future study to define the types of stress and the types of illness related to them.

The relation between short term stress and use of medical care proved to be of a complex nature. Illness functions obviously as an important intervening variable, but even when this variable is controlled, there are definite relations. A further intervening variable is availability. For some places where care is given (e.g., the private office) the effect is nil, but in the public section of medicine (OPD) and for telephone and emergency room visits (regardless of whether private or public) "stress-related illness" doubles the probability of medical contact at these places. The length of the illness episode is also of importance. The complexity of these relations could not be detected with normal survey methods. New data gathering techniques like the calendar and new analytic techniques like the identification of episodes and the use of Markov chain models were required.

What does this mean for the organization of health services? First, that medical care or rather health care must become more skilled at diagnosis and management of environmental crises, both to help prevent illness and assist in the proper management of illness for patients under stress. Caplan's "Crisis Intervention" theory [1] postulates that times of family crises are opportune ones for medical intervention. We must be able to diagnose these when the patient presents himself for medical care. It has long been clear to clinicians [2] that severity of illness alone is not the only reason why people seek help. It seems reasonable that the physician's ability to help his patient will be increased if he learns to deal more effectively with these precipitating causes of medical contacts. Knowledge of where, what type, and how often these crisesrelated medical contacts are occurring, and how far back in time the physician may have to search to identify such contacts, will alert him to their presence and nature. That this is more true in public clinics than in private offices reflects in part the greater burden of crises among this segment of the population. It remains for an experimental study to show that crisis intervention improves the health of the patient. At least it provides more intellectual interest and consid- erable reduction of hostility in the doctor who is asked to see a child with a minor illness if he understands that family stress may be the reason for the visit rather than the illness itself.

Second, since most of these crises are intrafamilial, it is clear that medical care, to manage them, must cross the boundaries between individuals. Whether this is best done by placing general medical care in the hands of the family physician or in the team of pediatricianinternist-obstetrician with allied professional help is less important than that such intrafamily stresses be diagnosed and considered in illness management. This requires that medical care is indeed accessible at the time of crisis. A more flexible appointment system would be required for the physician to be available on short notice. It also raises important issues in the current debate over how to manage the "Worried Well" [6]. Garfield [6] proposes that these patients (who are very likely to have such stress as a precipitator of contact in the public sector) be separated by automated multiphasic screening and cared for in a separate health maintenance area. We doubt that this more technical type of care will meet such patients' needs. Since they more likely present in the emergency room or by telephone, health screening would be difficult to use to separate the ill from the "Worried Well."

Finally, there is the philosophic question of how best to deal with such stress-induced contacts. It is still an open question whether we should aim to reduce stress or to "immunize" patients against it by strengthening the patients' ability to handle stress. As professionals we may be limited to the latter, although privately we may work for any social policy that helps to reduce external stressors like bad housing or unemployment. It seems unlikely that we will ever eliminate stress (or even should), and our goal should be to educate children and families to manage the inevitable stresses of life without a major increase in physical or mental illness. Knowledge of disease processes and their management is important, but knowledge of patient behavior processes and their direction are equally relevant to handle the "new morbidity" of our times and to lead to the new frontier of effective preventive care.

\section{References and Notes}

1. CAPLAN, G.: An Approach to Community Mental Health. (Tavistock Publishers, London, 1961)

2. CLYNE, M. D.: Night Calls: A Study in General Practice. (Tavistock Publishers, London, 1961). 
3. DODGE, D. L., AND MARTIN, W. T.: Social Stress and Chronic Illness. (University of None Dame Press, Notre Dame, 1970).

4. FRIEDMAN, S. G., AND GLASGOW, L. A.: Psychologic factors and resistance to infectious disease. Pediat. Clin. N. Amer., 13: 315 (1966).

5. FRIEDMAN, S. B., GLASGOW, L. A., AND ADER, R.: Psychological factors modifying host resistance to experimental infections. Ann. N. Y. Acad. Sci., 164: 381 (1969).

6. GARFIELD, S.: The delivery of medical care. Sci. Amer., 222. 15 (1970).

7. HINKLE, L. E., JR., CHRISTENSON, W. N., KANE, F. D., OSTFELD, A., THETFORD, W. N., AND WOLFF, H. G.: An investigation of the relation between life experience, personality characteristics, and general susceptibility to illness. Psychosom. Med., 20: 278 (1958).

8. HOLMES, T. H., HAWKINS, N. G., BOWERMAN, C. E., ClARKE, E. R., JR., AND JOFFE, J. R.: Psychosocial and psychophysiologic studies of tuberculosis. Psychosom. Med., 19: 134 (1957).

9. HOLMES, T. H., AND RAHE, R. H.: Social readjustment rating scale. J. Psychosom. Res., 11: 213 (1967).

10. KEMENY, J. G., AND SNELL, J. L.: Finite Markov-Chains. (Van Nostrand, Princeton, N. J., 1960).

11. LAZARUS, R. S.: Psychological Stress and the Coping Process. (McGraw-Hill, New York, 1966).

12. LEVINE, S., AND SCOTCH, N. A. (Editors): Social Stress. (Aldine Publishing Company, Chicago, 1970).

13. MCGRATH, J. E. (Editor): Social and Psychological Factors in Stress. (Holt, Rinehart, and Winston, New York, 1970).

14. MAZUR, A., AND ROBERTSON, L.: Biology and Social Behavior. (The Free Press, New York, 1972).

15. MECHANIC, D.: Students under stress. (Free Press, New York, 1962).

16. MECHANIC, D.: Response factors in illness: the study of illness behavior. Soc. Psychiat., 1: 11 (1966).
17. MECHANIC, D., AND VOLKART, E. H.: Stress, illness behavior and the sick role. Amer. Sociol. Rev., 26: 51 (1961).

18. MEYER, R. J., AND HAGGERTY, R. J.: Streptococcal infections in families: Factors altering individual susceptibility. Pediatrics, 29: 539 (1962).

19. ROGHMANN, K. J., AND HAGGERTY, R. H.: The diary as a research instrument in the study of health and illness behavior: Experiences with a random sample of young families. Med. Care, 10: 143 (1972).

20. SKIPPER, J. K., AND LEONARD, R. C: Children, stress and hospitalization: A field experiment. J. Health Soc. Behav., 9: 275 (1968).

21. Interview forms are available from the authors.

22. Diary forms are available from the authors.

23. Examples of severe stress (weight 3) are: lost job, child kicked out of school, car accident, divorce, unwanted pregnancy, separation, death in close family, etc. Examples of medium stress (weight 2) are: trouble with boss, car broke down, argument with husband, loan foreclosure, etc. Examples of mild stress (weight 1) are: children whiny, neighbors complaining, out of money, can't get along with fellow workers, etc

24. A Markov chain is den̂ned as a sequence of experiments (e.g., days) with a finite number of outcomes (e.g., stress states), in which the probability of a specific outcome (presence or absence of stress) is not necessarily independent of the outcome of the experiment immediately preceding it, but independent of the outcome of experiments before the one preceding it.

25. This research was supported by Grants nos. HS-00467 and HS47.266, Public Health Service, Health Services and Mental Health Administration, Rockville, Md.

26. Requests for reprints should be addressed to: KLAUS J. ROGHMANN, PhD., Department of Pediatrics, University of Rochester, Rochester, N. Y. 14620 (USA).

27. Accepted for publication December 21,1972. 